\title{
Influence of Cellular Lattice Body Structure on Gear Vibration Induced by Meshing
}

\author{
Riad Ramadani1,* - Marko Kegl ${ }^{2}$ - Jožef Predan² - Aleš Belšak ${ }^{2}$ - Stanislav Pehan² \\ 1 University of Prishtina, Faculty of Mechanical Engineering, Kosovo \\ 2 University of Maribor, Faculty of Mechanical Engineering, Slovenia
}

This paper discusses the influence of a gear body structure on gear vibrations induced by meshing. For this purpose the spur gear body was designed as cellular lattice structure. In order to reduce the stress levels as much as possible and to remove stress concentrations, the lattice structure was optimized by engaging a topology optimizer. The obtained lattice structure was expected to have a positive influence on vibrations reduction due to longer pressure waves travelling paths and several path direction changes. To verify this experimentally, the spur gear was produced from titanium alloy Ti-6Al-4V ELI by using selective laser melting technique. Furthermore, a new precise closed loop test rig was designed and produced to measure experimentally vibrations caused by rotating and lubricated gear pairs. Vibrations input data were obtained by measuring accelerations on the housing of the test rig. The signals were analyzed in frequency and time-frequency domains. Experimental results confirm that the cellular lattice structure of the gear body, especially if the voids are filled with a polymer, has a positive effect on reduction of vibrations induced by meshing of engaged gears.

Keywords: gear vibration, cellular lattice structure, topology optimization, test rig, signal analysis

Highlights

- $\quad$ The body of a spur gear was designed as a cellular lattice structure.

- A spur gear with optimized lattice body structure was produced using selective laser melting technique.

- A closed-loop test rig for testing gear pairs was developed and produced.

- The time signals of acceleration were analyzed in frequency and time-frequency domain.

- Experimental measurement of acceleration has verified that cellular lattice structure and polymer inserted into it, can effectively reduce gear vibration.

\section{INTRODUCTION}

Gears are primary components in many transmission applications. Therefore, the reduction of noise and vibration, generated by engaged gears, is of great importance. Gear vibrations are induced by external and internal influences. Typical external sources are time variable driving torque and speed. On the other hand, the internal sources originate from tooth meshing [1] and [2]. This process is plagued by stiffness variation (due to variable number of teeth engaged) and interacting teeth impacts [3] and [4] due to deformation, wear, and imperfections. In this way each toothed gear ring becomes an internal generator of vibrations.

Gear vibrations are transmitted to the housing by shafts and bearings, which creates annoying noise and decreases the quality of transmission operation. Consequently, any measure that may potentially reduce vibrations is worth of being investigated.

Earlier research work on gear vibration reduction was focused mainly on tooth profile modification [5] and [6]. More recently, this work was enriched by introducing sophisticated optimization procedures with the aim to improve tooth flanks [7] to [9].
Progress and improvements were achieved, but regardless of any profile or flank modification, tooth meshing still remained a generator of vibrations.

An interesting and successful vibration reduction was achieved by using a gear pair with phasing [10]. Such gears run smoothly but they are comparatively heavier as plain gears due to the complicated inner structure.

Another approach, taken by some authors [11] and [12], was an attempt trying to reduce gear vibrations by improving the function of the gear body. For example, a convenient powder material was used to fill the bores in the gear body. To some extent this was successful because this hinders the pressure wave propagation and induces some damping.

Till now the aim of majority of modifications related to the gear body was to reduce the weight of the gear. Weight reduction resulted in thinner walls and introduction of holes. These measures reduced the weight of the gear but did not have any significant impact on vibration generation and emission. From the dynamic point of view, a weaker and slimmer gear body might even make the situation worse [13].

So far, all investigations related to gear vibration reduction were based on the assumption that the 
gear has to be produced by known conventional technologies. However, in recent years new additive manufacturing (AM) technologies came into foreground and the impressive development of these technologies opened new potentials and approaches to structural design. This was accompanied by a respectful development of numerical optimization methods, focused on the potential benefits offered by the new AM technologies. This opened up a completely new perspective of how to address the design of structural parts.

The aim of this paper is to engage the newly emerged production technologies and optimization software in order to address gear body design. The objective is to design a light-weight gear body that will exhibit low generation of vibrations and will of course fulfil adequate load-carrying, stiffness, and strength requirements. Additionally, the gear body should contain sufficient empty space that could potentially be filled by a suitable polymer with the aim to achieve additional vibration reduction.

In this work the gear body is designed as a cellular lattice structure. Such a structure prolongs the pressure wave traveling paths and the traveling direction is often changed. Longer paths dissipate more energy due to internal friction and direction changes also influence positively energy dissipation. It is therefore expected, that such a design could exhibit good vibration reduction properties.

A loaded lattice structure can easily exhibit stress concentrations, especially at lattice joints. This should be avoided by all means because stress concentrations could easily induce crack initiation, which could lead to structural failure. To remove stress concentrations and to lower the stress levels to a minimum, a topology optimizer CAESS ProTOp was engaged. This high-performance topology optimizer enables to configure numerically a solid part as a lattice structure. The configured design is immediately ready for optimization, where material is redistributed so that stress concentrations are removed and stress levels reduced as much as possible.

An optimized lattice structure can typically be produced only by AM technologies. Therefore, in this work the obtained optimal spur gear was produced by selective laser melting (SLM) technique. This gear was then tested on a closed loop test rig. Although, various rigs have been used to test the dynamic behavior of gears so far [14] and [15], in this work a special test rig was developed in order to enable precise and simultaneous measurements of displacement, sound pressure, and acceleration during gear operation. The acceleration was measured on the housing and the signals taken from the accelerometer were analyzed in frequency and time-frequency domains; choosing these domains is typically the most useful approach in gear vibration analysis [16] to [18]. The recorded signals were processed within LabView.

This paper is organized as follows. In Section 1 gear body design and optimization is described briefly. Section 2 describes the developed test rig and measurements setup. Sections 3 is devoted to frequency and time-frequency analysis.

\section{DESIGN AND OPTIMIZATION OF GEAR BODY STRUCTURE}

In this work a spur gear corresponding to the data shown in Table 1, was addressed.

The diameter of the fixing hole was $25 \mathrm{~mm}$ and the adopted nominal torque was $200 \mathrm{Nm}$.

The numerical finite element analysis (FEA)ready model of the gear with a full solid body was prepared in SIMULIA Abaqus [19]. A linear elastic and isotropic material was selected.

Table 1. Basic data of a spur gear

\begin{tabular}{lc}
\hline Data & Value \\
\hline Number of teeth & 34 \\
\hline Module & $2.5 \mathrm{~mm}$ \\
\hline Pressure angle & $20^{\circ}$ \\
\hline Width & $10 \mathrm{~mm}$ \\
\hline Pitch diameter & $85 \mathrm{~mm}$ \\
\hline Base diameter & $79.874 \mathrm{~mm}$ \\
\hline Root diameter & $78.558 \mathrm{~mm}$ \\
\hline Tip diameter & $90 \mathrm{~mm}$ \\
\hline Module of elasticity & $206,000 \mathrm{MPa}$ \\
\hline Poisson's ratio & 0.3 \\
\hline
\end{tabular}

The gear was meshed with linear hexahedral elements of type C3D8, which are eight-node isoparametric elements with 24 displacement degrees of freedom. Hexahedral elements were used because the generated mesh exhibited symmetries which influence positively the symmetries of the final design. Due to the planned topology optimization, the generated mesh needed to be finer than typically engaged for usual FEA. Consequently, the number of elements was relatively high; the mesh contained a total of 2,918,412 elements. To influence positively the design symmetries and cyclic lattice pattern, a total of 68 static load cases were defined: one load case per one side of each tooth.

The applied load was calculated from the nominal torque, which was converted into pressure of $p=$ $618 \mathrm{MPa}$ and applied to a tooth flank. The loading 
a)

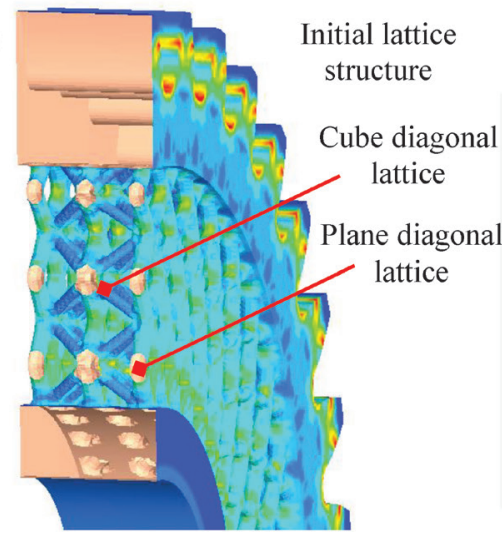

b)

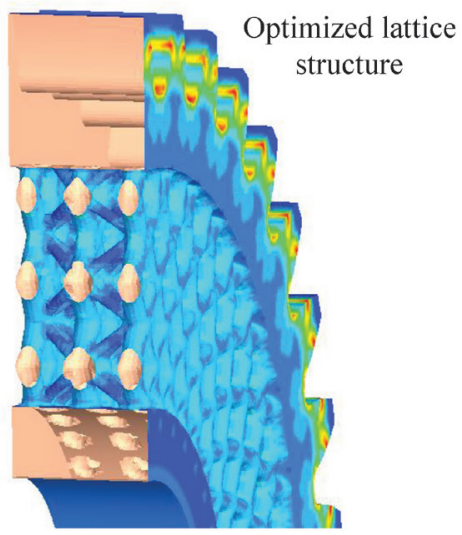

Fig. 1. Von Misses stress; a) of initial lattice structure, and b) of optimized lattice structure

point was the outer single meshing point. The inner surface of the hub was fixed by adequate displacement constraints. This solid body FEA model was then imported into CAESS ProTOp [20] for further design configuration and optimization.

According to [21] topology optimization of a lattice structure modeled by solid finite elements differs from conventional topology optimization in one crucial step: configuring of the optimization domain. This configuration step enforces the chosen lattice structure on a usual solid domain meshed by solid finite elements and prevents the optimizer to add material outside of the domain of the lattice structure.

To reconfigure the solid gear body into a cellular lattice structure, two different lattice cell types have been chosen; a cube diagonal lattice cell and a plane diagonal lattice cell. The lattice structure has been defined in the cylindrical coordinate system. The inner part of the gear body was designed by using a cube diagonal lattice cell, while for the outer part of the gear body a plane diagonal lattice cell was used (Fig. 1).

A structure configured in ProTOp is immediately ready for topology optimization. The process is iterative and each iteration requires one full finite element analysis per load case and one computation of topology parameters. In our case each iteration required 68 full finite element (FE) analyses. A detailed explanation for cell parameters used to design and optimize the gear body structure can be found in [22].

The stresses corresponding to the initial configured design with a volume part of $41.2 \%$ exhibited peak levels about $590 \mathrm{MPa}$ (Fig. 1; gear tooth region), while the stresses within the lattice structure reached maximum levels about $400 \mathrm{MPa}$ (Fig. 1; yellow color). The structure was then optimized and the volume part of the free domain was increased from $41.2 \%$ up to $49.3 \%$. Surprisingly this also reduced stresses within the tooth region, which now peaked to about $550 \mathrm{MPa}$. More importantly, however, are the stress levels within the optimized lattice structure. These stresses dropped dramatically with maximum stress levels reaching now only about $150 \mathrm{MPa}$.

The optimized structure exhibited drastically reduced stress levels and thus represents a good design from the mechanical point of view. From the technological point of view, however, it can practically not be produced by any of the conventional technologies. Therefore, the optimized spur gear was produced by using a titanium alloy Ti-6Al-4V ELI powder and the AM technology called the SLM technique. SLM allows a part to be built additively, layer by layer, from an adequate provided powder metal [23].

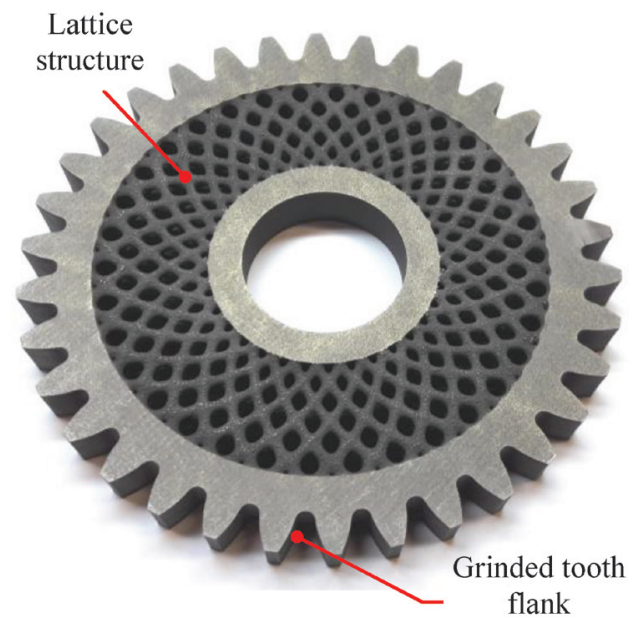

Fig. 2. AM-produced optimized titanium gear 
The parameters that have been used to produce the gear were: laser power $75 \mathrm{~W}$, scan speed 600 $\mathrm{mm} / \mathrm{s}$, and layer thickness $35 \mu \mathrm{m}$.

The teeth flank and the inner surface of the hub were grinded in the same tolerances as the gear with a solid body. The AM-produced titanium gear is shown in Fig. 2.

\section{DEVELOPMENT OF GEAR TEST RIG}

A completely new closed-loop test rig for gear vibration measurements was developed and manufactured in order to meet all internal requirements and cover all planned activities.

\subsection{Design and Operation}

The test rig consists of two heavy steel blocks, which are firmly connected with two connecting shafts; these components form a very rigid frame. Heavy-duty rotating components are firmly positioned into the steel blocks and the test gears are mounted from the outside. In this way, it is not necessary to disassemble the bearing system to replace the tested gear pair. The axial distance between the shafts is $90 \mathrm{~mm}$, Fig 3 .

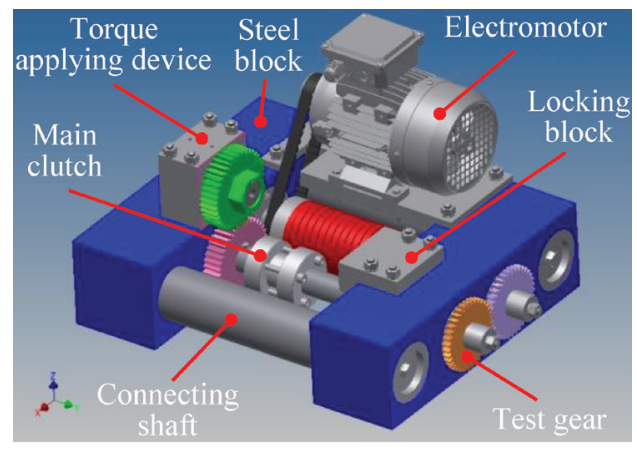

Fig. 3. Layout of the gear test rig

The closed-loop consist mainly of two shafts connected by two gear pairs. One gear pair just transmits the load torque from one shaft to the other; the other gear pair is the tested one. One shaft includes a clutch and the other shaft includes a torsional spring. The load torque is applied with a plain digital torque wrench while the clutch is open and one side of the clutch is firmly tightened by the locking block. At the desired torque level, the clutch is closed and the locking block and torque applying device removed from the test rig. The test rig is run by an electric motor and the RPM is controlled by a plain frequency regulator. To enable monitoring of lubrication conditions a special partly transparent and easy removable housing was made. Depending on the equipment this system enables simultaneous displacements, sound pressure, and acceleration measurements.

\subsection{Experimental Setup}

To measure the vibrations, the National Instruments NI PXI 4472 system and the PCB accelerometer (model 356A32) were used. The accelerometer was placed on the steel block. The signals taken from the accelerometer were transmitted to the data acquisition system and then to the computer for signal data analysis.

The test rig was placed on a firm table and a rubber layer was placed between the table and the steel blocks to isolated the test rig from any external vibrations. The experimental setup is shown in Fig. 4.

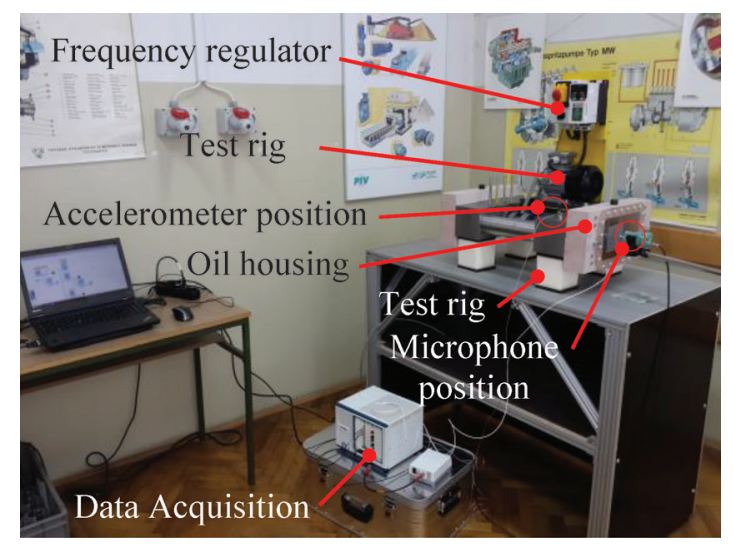

Fig. 4. Experimental setup

The vibration measurements were performed with 3 different gear pairs as follows:

- S-S gear pair is a reference pair consisting of two usual solid body gears;

- S-L gear pair consists of a usual solid body gear and of a gear with optimized lattice structure body;

- S-LP gear pair is the same as S-L gear, except that the void regions between lattices are filled with a polymer.

The S-L gear pair is shown in Fig. 5.

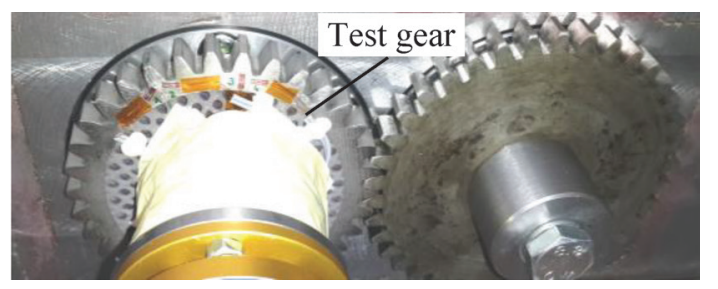

Fig. 5. The S-L gear pair mounted on the test rig 


\section{ACCELERATION FREQUENCY AND AMPLITUDE ANALYSIS}

In order to estimate the dynamic behavior of various gear pairs, the measured acceleration signals were analyzed. For this purpose, the original accelerations given in the time domain were transformed to the frequency and time-frequency domains.

\subsection{Frequency Domain Analysis}

Conventionally, this is achieved by using the Fourier transformation by which a time-dependent quantity $x(t)$ can be represented in the frequency domain by its Fourier transform (FT) $X(f)$ defined as [24]:

$$
X(t)=\int_{-\infty}^{+\infty} x(t) \cdot e^{-j 2 \pi f t} d t
$$

where $f$ is the frequency to analyze and $j$ is the imaginary number [24]. For a computer implementation, this function is replaced by the discrete Fourier transform (DFT), which can be obtained by numerical integration of Eq. (1) as [24]:

$$
X\left(f_{k}\right)=\int_{i=0}^{N-1} x\left(t_{i}\right) \cdot e^{-j 2 \pi f_{k} t_{i}}\left(t_{i+1}-t_{i}\right), \quad k=1, \ldots, N,
$$

where $f_{k}$ is the frequency of the $k^{\text {th }}$ harmonic. For computational efficiency reasons, the DFT is typically computed by using the fast Fourier transformation
(FFT). This procedure delivers amplitudes at discrete frequencies of the underlying harmonics. In the case of gear pairs the gear mesh frequency is known to be the fundamental frequency or the first harmonic. The dynamic behavior of engaged gears is characterized from the distribution of exposed frequencies (the ones with significant amplitudes).

To estimate the dynamic behavior of tested gear pairs, time signals from an accelerometer placed on the housing were acquired. The applied torque was $T=60 \mathrm{Nm}$ and the number of rotations was $n=$ $310 \mathrm{rpm}$. This means that the fundamental frequency was $f_{1}=176 \mathrm{~Hz}$. The frequencies were analyzed up to $7 \mathrm{kHz}$, while the measured time signal was $0.2 \mathrm{~s}$ long. The time signals are converted to frequency and timefrequency domains by using LabView.

The acceleration time signal of the reference S-S gear pair is shown in Fig. 6, whereas its frequency spectrum is shown in Fig. 7. From the frequency spectrum it is evident that the dominating amplitude appeared at the $5^{\text {th }}$ harmonics $f_{5}=5 f_{1}=880 \mathrm{~Hz}$. The other frequencies with notable amplitudes were those corresponding to the $1^{\text {st }}, 3^{\text {rd }}$, and $8^{\text {th }}$ harmonics. The frequency components after $8^{\text {th }}$ harmonics are observable but relatively low.

The acceleration time signal for the S-L gear pair with lattice structure is presented in Fig. 8, whereas its frequency spectrum is given in Fig. 9.

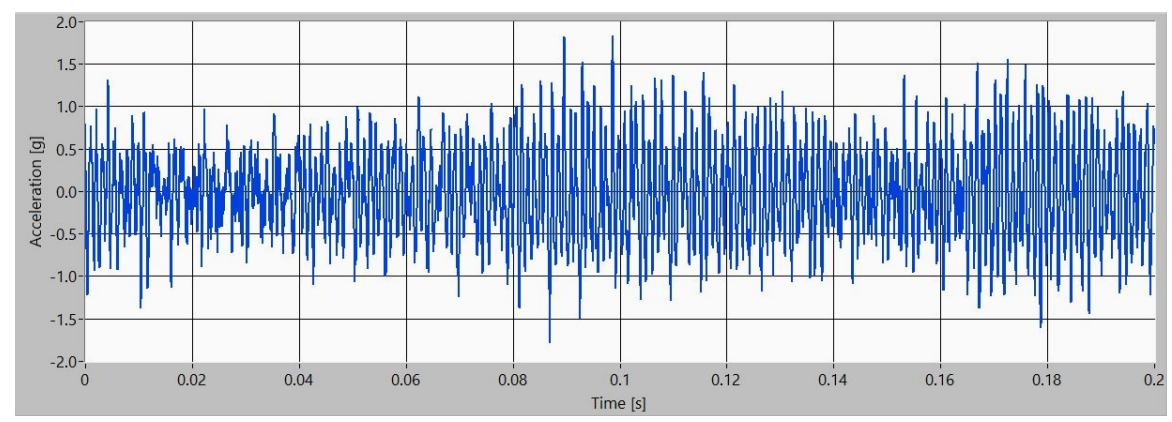

Fig. 6. Time signal of acceleration for the reference S-S gear pair

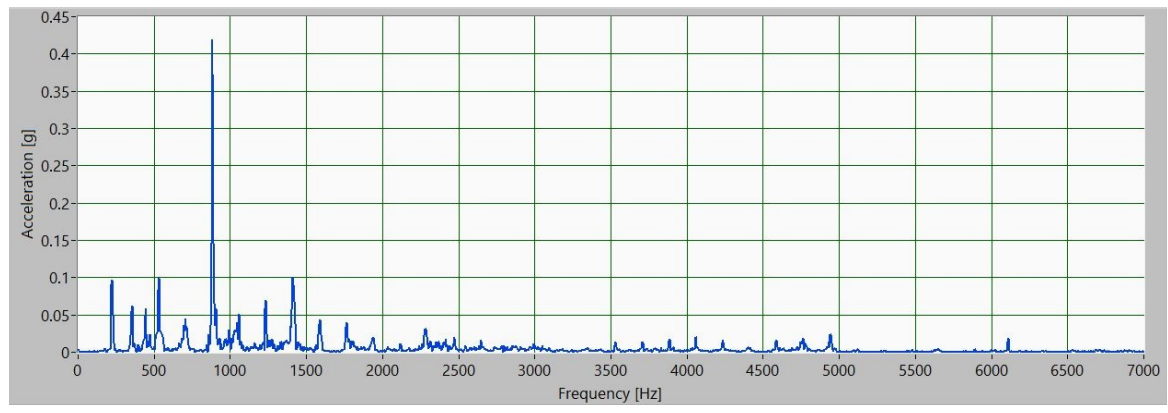

Fig. 7. Frequency spectrum of acceleration for the reference S-S gear pair 
One can see from the frequency spectrum that the dominating amplitude is now the one corresponding to the $6^{\text {th }}$ harmonics $f_{6}=6 f_{1}=1056 \mathrm{~Hz}$. An only somewhat lower amplitude is now observed for the $3^{\text {rd }}$ harmonics. Still somewhat lower but nicely exposed are the $7^{\text {th }}, 8^{\text {th }}$, and $9^{\text {th }}$ harmonics.

The acceleration time signal for the S-LP gear pair with lattice structure and filled with polymer is shown in Fig. 10; its frequency spectrum is shown in Fig. 11. One can see that the frequencies of the $6^{\text {th }}$ and $9^{\text {th }}$ harmonics are the dominating ones. A somewhat lower but nicely notable frequencies are those of the $4^{\text {th }}$, and $5^{\text {th }}$ harmonics.

As shown in Fig. 7. the largest amplitude was observed for the S-S gear with a solid body; a peak of approximately $0.42 \mathrm{~g}$ appeared at the frequency of 880 Hz. For the S-L gear pair with lattice structure (Fig. 9), the maximal amplitude was substantially lower; a peak of around $0.26 \mathrm{~g}$ appeared at the frequency of $1056 \mathrm{~Hz}$. A further reduction of the maximal amplitude value was achieved by filling the void regions within the lattice structure with a polymer (Fig. 11). The S-LP gear pair exhibits a maximum of $0.165 \mathrm{~g}$ at the frequency of $1056 \mathrm{~Hz}$.

By comparing the frequency spectrums of all tested gear pairs (Fig. 7, 9, and 11), one can see that the dominant frequency amplitude is the highest and notable frequency components are relatively widely spread for the solid body gear. A lattice structure of the gear body obviously lowers the maximum amplitude and the amplitudes of all notable harmonics are more equilibrated. This trend is even more observable for the lattice-polymer gear, whose spectrum also indicates an obvious reduction of vibration energy. This example indicates that a lattice body structure can potentially do a good job in reducing gear vibrations. It looks also that the inserted polymer is quite efficient in increasing the structural damping, which also helps a lot.

\section{2 "Time-Frequency Domain Analysis}

In the spectrum of the frequency domain, it is possible to determine, which frequencies were present in the signal but it is not possible to know the time when those frequencies appeared. The time-frequency analysis introduces the time variable and makes it possible to determine how those frequencies of nonstationary signals change with time, and what the levels of signal energy are [25]. Time-frequency analysis is a three-dimensional time, frequency, and amplitude representation of a signal. The short time Fourier transformation (STFT) is a linear timefrequency transformation and it is used for analyzing non-stationary signals. The basic idea of STFT is to divide a signal into short time segments, and then

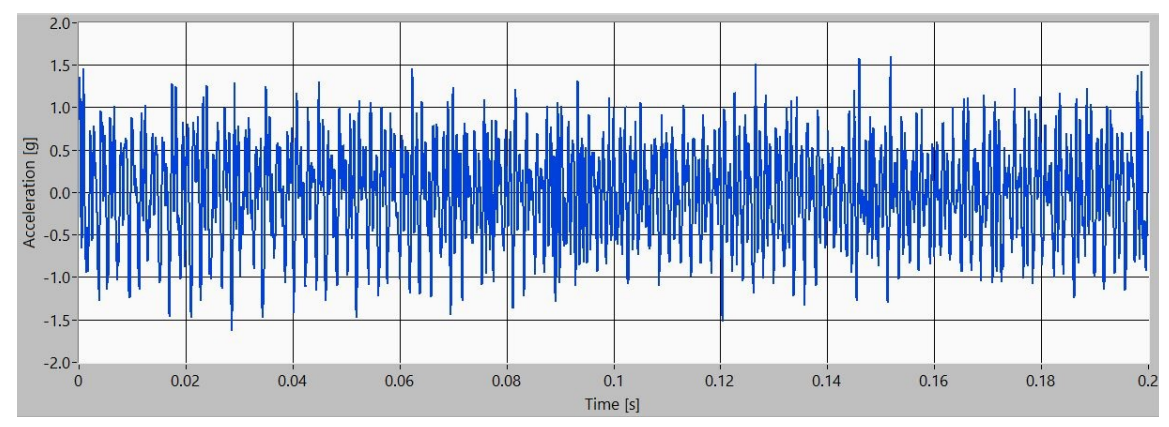

Fig. 8. Time signal of acceleration for the S-L gear pair

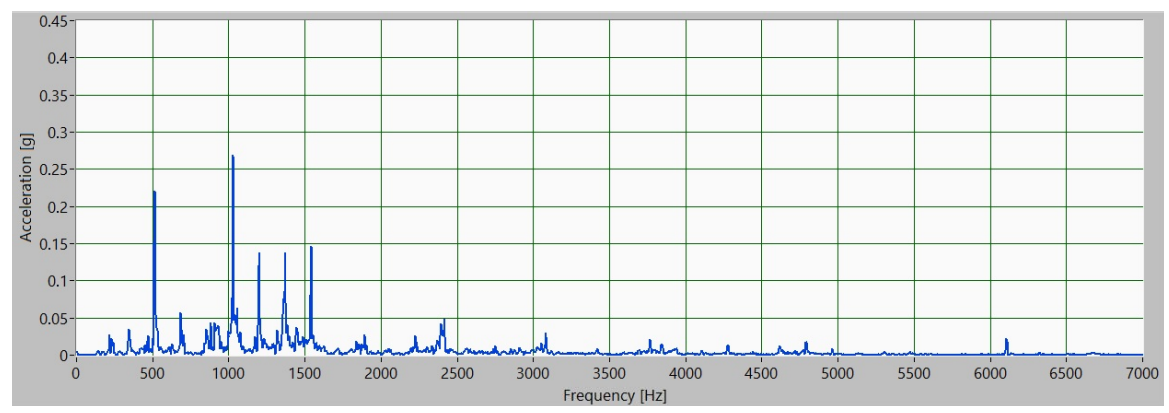

Fig. 9. Frequency spectrum of acceleration for the S-L gear pair 


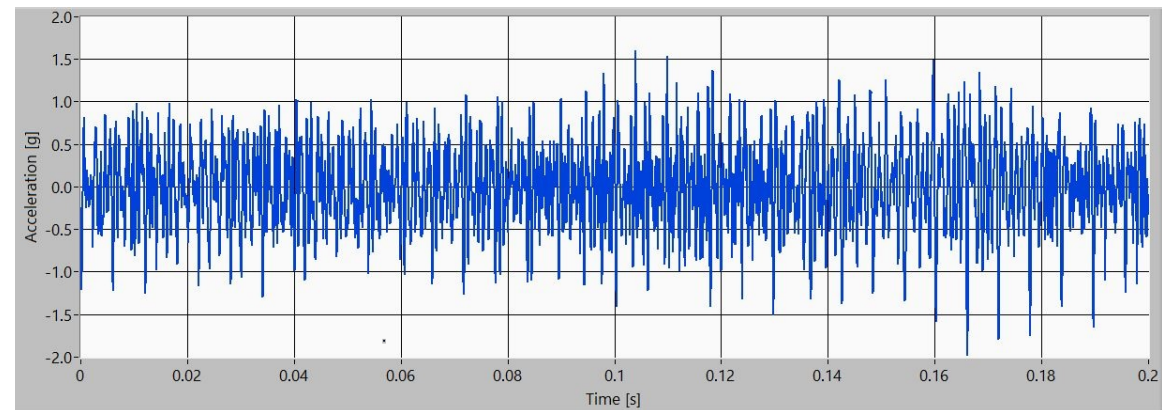

Fig. 10. Time signal of acceleration for the S-LP gear pair

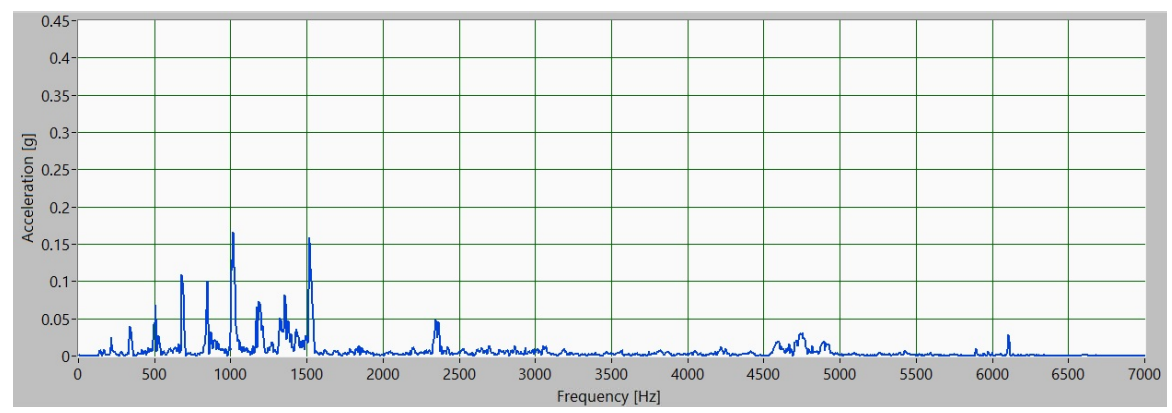

Fig. 11. Frequency spectrum of acceleration for the S-LP gear pair

the Fourier analysis is carried out for each segment separately. It is assumed that signals are stationary within each segment. The STFT is obtained in the following way: for any signal $x(t)$, let's suppose that $w(\tau-t)$ is a window function centered at the time $t$, to produce a segmented signal $x(\tau) w(\tau-t)$, where $\tau$ is a time variable. By applying the FFT to each of such segmented signals, the STFT is obtained as [26]:

$$
\operatorname{STFT}_{x}(t, f)=\int_{-\infty}^{+\infty} x(\tau) \cdot w(\tau-t) e^{-j 2 \pi f t} d \tau .
$$

The time window type and positioning must be selected properly in order to get a good compromise between good time and frequency resolution of the result.

For reference S-S gear pair with a solid body, the time-frequency spectrogram is presented in Fig. 12. Although the result is smeared over time and frequency, one can roughly estimate that the dominating $5^{\text {th }}$ harmonic of acceleration is present in about $62 \%$ of the time interval (Fig. 12; red color). One can also see that the $5^{\text {th }}$ harmonic is not stable, but exhibits an occasional vanishing and pulsating character.

For the S-L gear pair with lattice structure the spectrogram is given in Fig. 13. One can see that the dominating $6^{\text {th }}$ harmonic of acceleration is present in about $45 \%$ of the time (Fig. 13; red color). The $3^{\text {rd }}$ harmonic with slightly lower amplitude can also be observed; however, its time presence is significantly lower. One can say that the $6^{\text {th }}$ harmonic is semi-stable with a pulsating character.

For the S-LP gear pair with polymer filled lattice structure the spectrogram is shown in Fig. 14. One can see that the dominating $6^{\text {th }}$ harmonic of acceleration is present in about $33 \%$ of the time (Fig. 14; red color). The amplitudes are also observable lower than in case of other gear pairs. The $6^{\text {th }}$ harmonic is semi-stable with a pulsating character.

When the time-frequency spectrograms of all tested gear pairs are compared, it is obvious that the notable frequency components of the S-S gear pair are longer present in time. This presence decreases for the S-L and even more for the S-LP gear pairs. A similar trend can be observed for the amplitudes, with the S-LP gear pair exhibiting by far the lowest amplitudes. Regarding the signal stability one can say that the lattice structure caused a more stable response in the sense that the dominating frequencies are more evenly present during the observed time interval.

At this point it might be worth noting that besides of reduced vibrations, the optimized lattice body gear also exhibits a substantially reduced mass. Namely, the volume of the gear with a solid body is about $51130 \mathrm{~mm}^{3}$, while the volume of the gear with the optimized lattice structure is about $32570 \mathrm{~mm}^{3}$. Thus, 


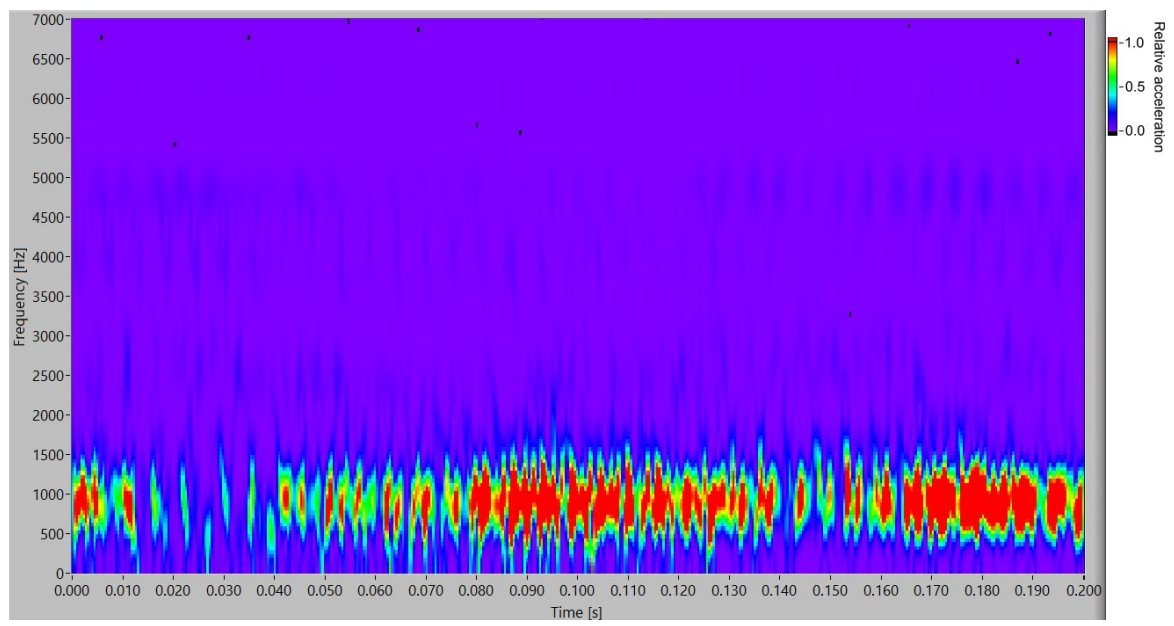

Fig. 12. Time-frequency spectrogram of acceleration for the S-S gear pair

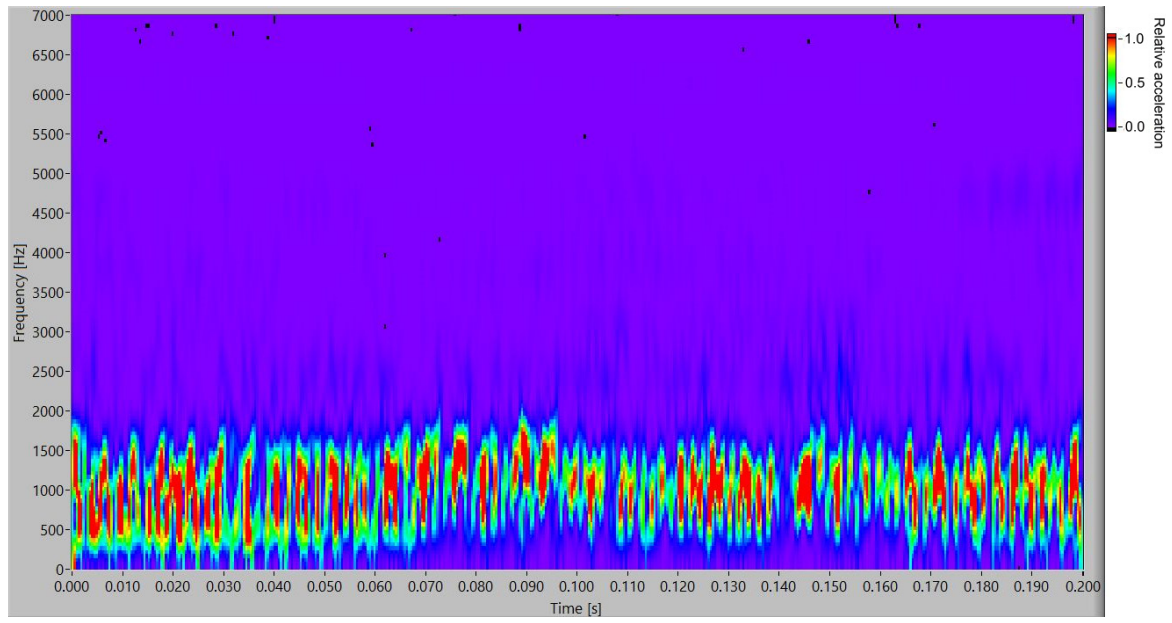

Fig. 13. Time-frequency spectrogram of acceleration for the S-L gear pair

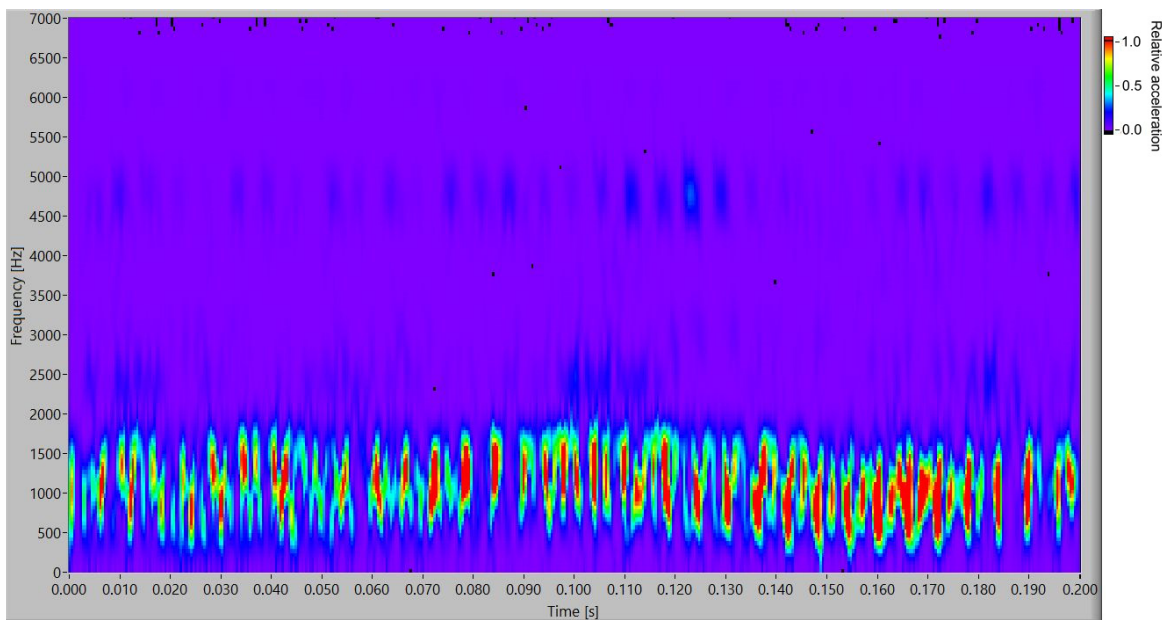

Fig. 14. Time-frequency spectrogram of acceleration for the S-LP gear pair

the volume of the used material is reduced by around one third. The weight of the gear with a solid body is
$0.40137 \mathrm{~kg}$, whereas the weight of the gear with the optimized lattice structure is $0.25567 \mathrm{~kg}$. 


\section{CONCLUSION}

A new approach to gear vibration reduction was presented, based on the gear body structure modification. The body structure was designed as a cellular lattice structure that was optimized for stress level and stress concentrations by employing topology optimization. A spur gear with optimized lattice structure was produced by using Selective Laser Melting technique.

To measure the dynamic behavior of such gears, a totally new closed-loop test rig has been developed and produced. The test rig enables to simultaneously measure displacement, sound pressure and acceleration, while the gears rotate.

According to experimental results of accelerations for the tested gears, it was proven that the lattice structure can effectively reduce gear vibration analyzed in frequency spectrum and time-frequency spectrogram. A lattice structure provides additionally a nice opportunity to be filled with an adequate polymer. According to the results, this may further reduce the vibrations.

The main disadvantage of a lattice structure is that currently it is a rather expensive choice since traditional manufacturing is not possible and consequently the new AM technologies have to be engaged. Additionally, the teeth flank of a printed gear must be grinded which requires an extra production operation. Another, less obvious, point of concern is that currently printed materials are not very resistant against fatigue crack initiation and consequent structural failure. To mitigate this drawback, a printed part has to be optimized by all means in order to reduce the stresses as much as possible.

\section{ACKNOWLEDGEMENT}

The article was written under favourable circumstances of Faculty of Mechanical Engineering, University of Maribor, Slovenia. The authors want to thank Erasmus Mundus JoinEU-SEE PENTA scholarship program, Slovenian Research Agency (research core funding No. P2-0063) as well as CAESS company for the research support.

\section{REFERENCES}

[1] Mohammed, O.D., Rantatalo, M., Aidanpää, J.O. (2013). Improving mesh stiffness calculation of cracked gears for the purpose of vibration-based fault analysis. Engineering Failure Analysis, vol. 34, p. 235-251, D0l:10.1016/j. engfailanal.2013.08.008.
[2] Saxena, A., Chouksey, M., Parey, A. (2017). Effect of mesh stiffness of healthy and cracked gear tooth on modal and frequency response characteristics of geared rotor system. Mechanism and Machine Theory, vol. 107, p. 261-273, D0I:10.1016/j.mechmachtheory.2016.10.006.

[3] Agemi, F.M., Ognjanovic, M. (2004). Gear vibration in supercritical mesh-frequency range. FME Transaction, vol. 32, p. 87-94.

[4] Ognjanovic, M., Agemi, F. (2010). Gear vibrations in supercritical mesh-frequency range caused by teeth impacts. Stojniški vestnik - Journal of Mechanical Engineering, vol. 56, no. 10, p. 653-662.

[5] Kahraman, A., Blankenship, G.W. (1999). Effect of involute tip relief on dynamic response of spur gear pairs. Journal of Mechanical Design, vol. 121, no. 2, p. 313-315, DOI:10.1115/1.2829460.

[6] Liu, G., Parker, R.G. (2008). Dynamic modeling and analysis of tooth profile modification for multimesh gear vibration. Journal of Mechanical Design, vol. 130, no. 12, p. 121402-13, DOI:10.1115/1.2976803.

[7] Faggioni, M., Samani, F.S., Bertacchi, G., Pellicano, F. (2011). Dynamic optimization of spur gears. Mechanism and Machine Theory, vol. 46, no. 4, p. 544-557, D0l:10.1016/j. mechmachtheory.2010.11.005.

[8] Ma, H., Pang, X., Feng, R., Wen, B. (2016). Evaluation of optimum profile modification curves of profile shifted spur gears based on vibration responses. Mechanical Systems and Signal Processing, vol. 70-71, p. 1131-1149, D0l:10.1016/j. ymssp.2015.09.019.

[9] Ghosh, S.S., Chakraborty, G. (2016). On optimal tooth profile modification for reduction of vibration and noise in spur gear pairs. Mechanism and Machine Theory, vol. 105, p. 145-163, DOl:10.1016/j.mechmachtheory.2016.06.008.

[10] Cheon, G.-J. (2010). Numerical study on reducing the vibration of spur gear pairs with phasing. Journal of Sound and Vibration, vol. 329, no. 19, p. 3915-3927, D0l:10.1016/j. jsv.2010.04.005.

[11] Xiao, W., Li, J., Wang, S., Fang, X. (2016). Study on vibration suppression based on particle damping in centrifugal field of gear transmission. Journal of Sound and Vibration, vol. 366, p. 62-80, D0I:10.1016/j.jsv.2015.12.014.

[12] Xiao, W., Huang, Y., Jiang, H., Jin, L. (2016). Effect of powder material on vibration reduction of gear system in centrifugal field. Powder Technology, vol. 294, p. 146-158, D0l:10.1016/j. powtec.2016.01.038.

[13] Li, S. (2008). Experimental investigation and FEM analysis of resonance frequency behavior of three-dimensional, thin-walled spur gears with a power-circulating test rig. Mechanism and Machine Theory, vol. 43, no. 8, p. 934-963, D0l:10.1016/j.mechmachtheory.2007.07.009.

[14] Arun A.P., Senthil kumar, A.P., Giriraj, B., Faizur rahaman, A. (2014). Gear test rig - A review. International Journal of Mechanical \& Mechatronics Engineering, vol. 14, no. 5, p. 1626.

[15] Åkerblom, M. (1999). Gear test rig for noise and vibration testing of cylindrical gears. Proceedings OST Symposium on Machine Design, p. 183-199. 
[16] Belsak, A., Flasker, J. (2006). Method for detecting fatigue crack in gears. Theoretical and Applied Fracture Mechanics, vol. 46, no. 2, p. 105-113, D0l:10.1016/j.tafmec.2006.07.002.

[17] Belsak, A., Flasker, J. (2008). Vibration analysis to determine the condition of gear unit. Stojniški vestnik - Journal of Mechanical Engineering, vol. 54, no. 1, p. 11-24.

[18] Mohammed, O.D., Rantatalo, M. (2016). Dynamic response and time-frequency analysis for gear tooth crack detection. Mechanical Systems and Signal Processing, vol. 66-67, p. 612-624, D0I:10.1016/J.ymssp.2015.05.015.

[19] Abaqus/CAE 6.14 User's guide. (2014). Dassault Systèmes Corp., Providence.

[20] CAESS ProTOp, from http://caess.eu/, accessed on 2018-0309.

[21] Harl, B., Predan, J., Gubeljak, N., Kegl, M. (2017). On configuration-based optimal design of load-carrying lightweight parts. International Journal of Simulation Modelling, vol. 16, no. 2, p. 219-228, D0l:10.2507/ijsimm16(2)3.369.
[22] Ramadani, R., Belsak, A., Kegl, M., Predan, J., Pehan, S. (2018). Topology optimization based design of lightweight and low vibration gear bodies. International Journal of Simulation Modelling, vol. 17, no. 1, p. 92-104, D0l:10.2507/ ijsimm17(1)419.

[23] Olakanmi, E,O., Cochrane, R.F., Dalgarno, K.W. (2015). A review on selective laser sintering/melting (SLS/SLM) of aluminium alloy powders: Processing, microstructure, and properties. Progress in Materials Science, vol. 74, p. 401-477, Dol:10.1016/j.pmatsci.2015.03.002.

[24] Brigham, E.O. (1988). The Fast Fourier Transform and Its Applications. Prentice Hall, Michigan.

[25] Boashash, B. (2003). Time Frequency Analysis. Elsevier Science, Amsterdam.

[26] Feng, Z., Liang, M., Chu, F. (2013). Recent advances in timefrequency analysis methods for machinery fault diagnosis: A review with application examples. Mechanical Systems and Signal Processing, vol. 38, no. 1, p. 165-205, D0l:10.1016/j. ymssp.2013.01.017. 